\title{
Interim estimates of 2014/15 influenza vaccine effectiveness in preventing laboratory-confirmed influenza-related hospitalisation from the Serious Outcomes Surveillance Network of the Canadian Immunization Research Network, January 2015
}

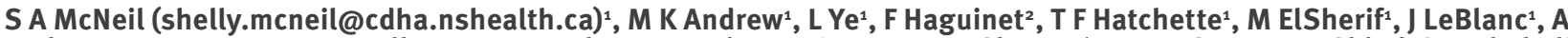
Ambrose $^{1}$, A McGeer ${ }^{3}$, J E McElhaney ${ }^{4}$, M Loeb ${ }^{5}$, D MacKinnon-Cameron ${ }^{1}$, R Sharma ${ }^{6}$, G Dos Santos ${ }^{7}$, V Shinde ${ }^{8}$, on behalf of the Investigators of the Serious Outcomes Surveillance Network of the Canadian Immunization Research Network (CIRN) ${ }^{9}$

1. Canadian Center for Vaccinology, IWK Health Centre and Capital Health, Dalhousie University, Halifax, Nova Scotia, Canada

2. GlaxoSmithKline Vaccines, Wavre, Belgium

3. Mount Sinai Hospital, Toronto, Ontario, Canada

4. Advanced Medical Research Institute of Canada, Sudbury, Ontario, Canada

5. McMaster University, Hamilton, Ontario, Canada

6. GlaxoSmithKline Vaccines, Mississauga, Ontario, Canada

7. Business \& Decision Life Sciences (on behalf of GlaxoSmithKline Vaccines), Brussels, Belgium

8. GlaxoSmithKline Vaccines, King of Prussia, Pennsylvania, United States

9. Investigators in the network (www.cirnetwork.ca) are listed at the end of the article

Citation style for this article:

McNeil SA, Andrew MK, Ye L, Haguinet F, Hatchette TF, ElSherif M, LeBlanc J, Ambrose A, McGeer A, McElhaney JE, Loeb M, MacKinnon-Cameron D, Sharma R, Dos Santos G, Shinde V, on behalf of the Investigators of the Serious Outcomes Surveillance Network of the Canadian Immunization Research Network (CIRN). Interim estimates of $2014 / 15$ influenza vaccine effectiveness in preventing laboratory-confirmed influenza-related hospitalisation from the Serious Outcomes Surveillance Network of the Canadian Immunization Research Network, January 2015. Euro Surveill. 2015;20(5):pii=21024. Available online: http://www.eurosurveillance.org/ ViewArticle.aspx?Articleld=21024

Article submitted on 23 January 2015 / published on 05 February 2015

The 2014/15 influenza season in Canada has been characterised to date by early and intense activity dominated by influenza $\mathrm{A}\left(\mathrm{H}_{3} \mathrm{~N}_{2}\right)$. A total of $99.0 \%$ (593/599) hospitalisations for laboratory-confirmed influenza with a known influenza virus type enrolled in sentinel hospitals of the Serious Outcomes Surveillance Network of the Canadian Immunization Research Network were due to influenza A. Of the 216 with a known subtype, influenza $A\left(\mathrm{H}_{3} \mathrm{~N}_{2}\right)$ accounted for $99.1 \%(n=214)$. Interim unmatched vaccine effectiveness (VE) estimates adjusted for age and presence of one or more medical comorbidities were determined by test-negative case-control design to be $-16.8 \%$ (90\% confidence interval $(\mathrm{CI}):-48.9$ to 8.3 ) overall and $-22.0 \%$ (90\% Cl: -66.5 to 10.7$)$ for laboratory-confirmed influenza $\mathrm{A}\left(\mathrm{H}_{3} \mathrm{~N}_{2}\right)$. Among adults aged under 65 years, the overall VE was $10.8 \%(90 \% \mathrm{Cl}:-50.2$ to 47.0) while in adults aged 65 years or older, the overall VE was $-25.4 \%$ (90\% Cl: -65.0 to 4.6$)$.

Clinical trial registration number: NCT01517191.

\section{Introduction}

In the 2014/15 influenza season, Canada has to date experienced early, intense influenza activity, with record numbers of long-term care facility outbreaks and a seasonal peak number of influenza-related hospitalisations, laboratory detections of influenza virus, and outpatient consultations for influenza-like-illness occurring in week 53 (28 December 2014 to 3 January 2015) [1]. Antigenic and genetic characterisation of the circulating influenza $A\left(\mathrm{H}_{3} \mathrm{~N}_{2}\right)$ strain viruses in both Canada and the United States (US) has demonstrated antigenic drift from the vaccine strain in a majority of characterised isolates, raising concern that vaccine effectiveness (VE) might be suboptimal [1]. In the US, interim VE estimates demonstrate limited effectiveness of the $2014 / 15$ vaccines in the prevention of laboratoryconfirmed, medically attended acute respiratory illness in persons of all ages, with adjusted VE estimates of $24 \%$ (95\% confidence interval (CI): 0 to 43 ) in children aged 6 months to 17 years, $16 \%$ ( $95 \% \mathrm{Cl}:-18$ to 41$)$ in adults aged 18 to 49 years and $23 \%$ (95\% Cl: -14 to 47 ) in adults aged 50 years and older [2]. In Canada, the Sentinel Physicians Surveillance Network recently published interim estimates of VE against laboratory-confirmed, medically attended influenza $\mathrm{A}$ and influenza $\mathrm{A}\left(\mathrm{H}_{3} \mathrm{~N}_{2}\right)$ of $-4 \%(95 \% \mathrm{Cl}:-45$ to 25$)$ and $-8 \%(95 \% \mathrm{Cl}$ : -50 to 23), respectively [3]. Interim estimates for $\mathrm{VE}$ in the prevention of laboratory-confirmed, influenzarelated hospitalisations have not yet been reported.

In Canada, annual influenza immunisation is recommended for all persons aged 6 months of age or older, with the primary goal of preventing influenza-associated hospitalisation and death [4]. The vast majority 
of influenza vaccine deployed in Canada is intramuscular, non-adjuvanted, trivalent inactivated influenza vaccine. Most immunisation programmes begin in mid-October.

Drifted influenza $\mathrm{A}\left(\mathrm{H}_{3} \mathrm{~N}_{2}\right)$ viruses were first detected in late March 2014, after the World Health Organization (WHO) recommendations for the 2014/15 northern hemisphere vaccine in mid-February [5]. The 2014/15 influenza vaccines used in Canada include $A / C a l i f o r n i a / 7 / 2009$ ( $\left.\mathrm{H}_{1} \mathrm{~N}_{1}\right)$ pdmo9like virus; A/Texas/50/2012 ( $\mathrm{H}_{3} \mathrm{~N}_{2}$ )-like virus; and $\mathrm{B} /$ Massachusetts/2/2012-like virus, as recommended by WHO and Canada's National Advisory Committee on Immunization [4]. Here, we provide an interim estimate of overall and age-stratified 2014/15 influenza VE in the prevention of laboratory-confirmed influenzarelated hospitalisation using a test-negative casecontrol design, based on patients who were admitted up to 10 January 2015 in the hospitals of the Serious Outcomes Surveillance (SOS) Network of the Canadian Immunization Research Network (CIRN).

\section{Methods}

\section{Hospital-based surveillance}

The CIRN SOS Network was established in 2009 to prospectively monitor annual seasonal influenza VE in the prevention of laboratory-confirmed influenza-related hospitalisation in adults hospitalised in Canada [6]. In this 2014/15 season, the network comprises 15 adult academic and community hospitals in five of the 10 Canadian provinces (namely New Brunswick, Nova Scotia, Quebec, Ontario, and British Columbia) accounting for about 9,000 adult acute-care hospital beds. There are no network hospitals in Canada's three territories. Beginning on 15 November 2014, trained SOS Network surveillance monitors enrolled all hospitalised cases of influenza diagnosed through routine testing occurring as part of usual standard of care. Active surveillance began the week in which two hospitalised influenza cases were identified in the local network hospital or the week when the local hospital or public health laboratory reported two of more positive influenza tests in one week. Active surveillance requires review of all daily admissions of adult patients (aged 16 years and older) to medical wards (e.g. internal medicine, geriatric medicine, family medicine, cardiology, pulmonology) and medical and coronary intensive-care units to identify eligible patients. Patients 16 years of age or older admitted with an acute respiratory illness (i.e. pneumonia, acute exacerbation of chronic obstructive pulmonary disease or asthma, unexplained sepsis, any other respiratory infection or diagnosis, or any respiratory or influenza-like symptom) were eligible for enrolment.

All eligible patients had a nasopharyngeal swab collected as part of routine clinical care or by the SOS Network monitor for testing for influenza by reversetranscription polymerase chain reaction (RT-PCR) or viral culture in the local hospital or public health laboratory according to routine local testing procedures. Patients were considered immunised if they reported receipt of a 2014/15 influenza vaccine more than two weeks before onset of their symptoms. Self-reported immunisation history was verified with the immunisation provider or an immunisation registry, providing that information was available. Detailed demographic information, medical and surgical history, history of present illness and hospitalisation and outcome details were collected from the patient and their medical record.

The study was approved by the research ethics boards of participating institutions and consent procedures followed local research ethics board requirements (clinical trial registration number: NCT01517191).

\section{Estimation of influenza vaccine effectiveness}

Eligible hospitalised patients admitted between 15 November 2014 and 10 January 102015 for whom results of influenza testing and self-reported 2014/15 influenza immunisation status were available were included in this interim analysis of VE. Patients with a positive laboratory test for influenza were defined as cases, while those testing negative for influenza within seven days of symptom onset were defined as controls.

Odds ratios (OR) for influenza vaccination among cases and controls were calculated and VE was estimated as $(1-O R) \times 100 \%$ by logistic regression adjusting for age and presence of one or more medical comorbidities [4]. Overall adjusted VE and VE stratified by age (patients 65 years or older vs patients younger than 65 years) are presented.

In the current interim analysis, VE estimates are not adjusted for site of enrolment. However, it is important to note that the same protocol is used in all participating sites and all enrolment is done by study staff trained and monitored by the central study team. Enrolment criteria for cases and controls, as well as sampling procedures, are standardised across sites.

We have included $90 \% \mathrm{Cls}$, as we consider these more appropriate than $95 \% \mathrm{Cls}$ for our purpose. The $90 \% \mathrm{Cl}$ is used to test our primary objective, which has a onesided alternative rather than a two-sided alternative. More specifically, we are interested in testing the null hypothesis of $\mathrm{VE} \leq \mathrm{o}$ (vaccine is not protective) vs the alternative hypothesis of $\mathrm{VE}>\mathrm{o}$ (vaccine is protective). We consider this is more appropriate than testing a null hypothesis of $V E=o$ (vaccine will neither increase nor decrease the risk of acquiring influenza) vs the alternative hypothesis of VE < or > o (vaccine will either increase or decrease the risk of acquiring influenza). Since the first hypothesis has a one-sided alternative, only the lower bound of the $\mathrm{Cl}$ matters. Since a $95 \%$ $\mathrm{Cl}$ controls $2.5 \%$ type I error on each side, it will make our test a $2.5 \%$-level test rather than a $5 \%$-level test. To aid comparison with other studies, however, we have 
Laboratory-confirmed influenza cases and test-negative controls admitted to hospitals of the Serious Outcomes Surveillance Network of the Canadian Immunization Research Network, by week and virus subtype, 15 November $2014-10$ January 2015 $(n=1,071)$

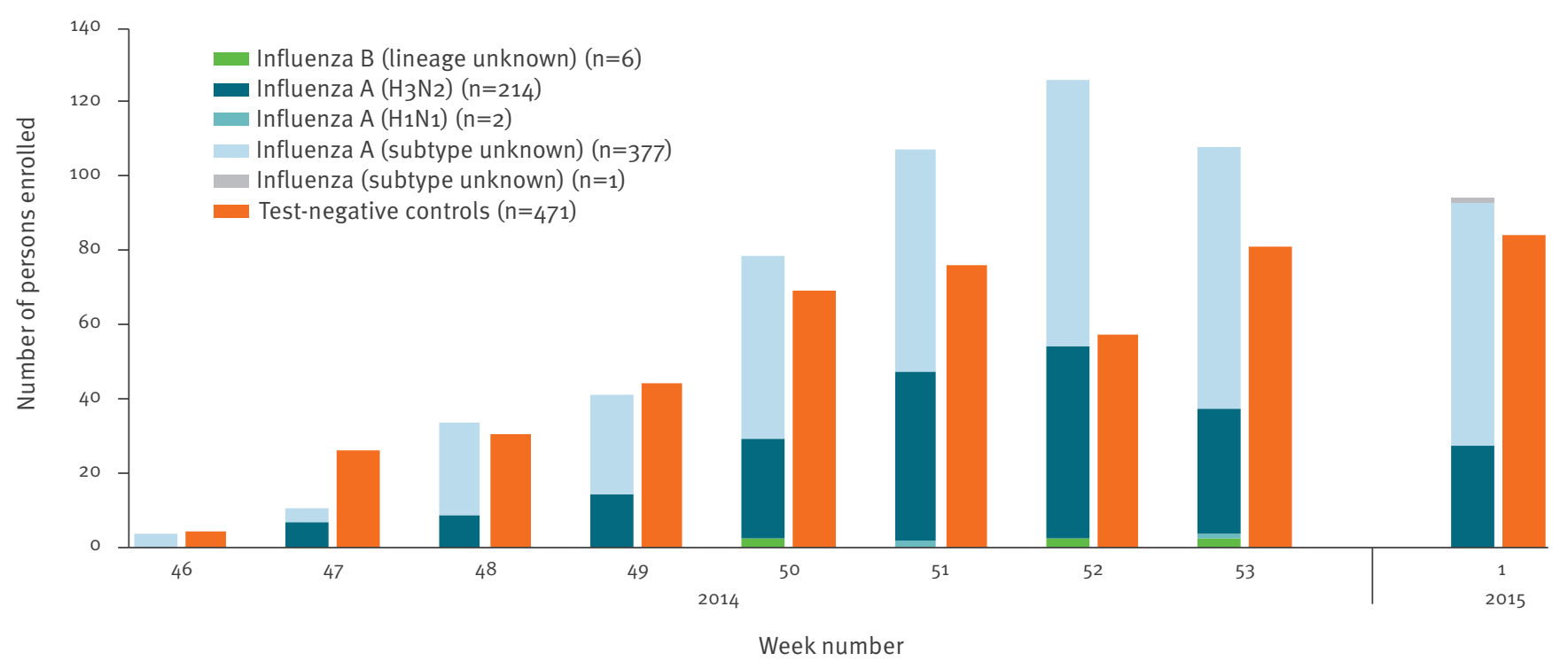

also included $95 \%$ Cls in the table displaying the VE estimates.

\section{Results}

Interim estimates of influenza vaccine effectiveness Between 15 November 2014 (week 46) and 10 January 2015 (week 1), 600 hospitalised influenza cases and 471 hospitalised test-negative controls were enrolled and included in the interim analysis. Laboratory-confirmed influenza cases and test-negative controls admitted to the SOS Network hospitals by week and virus subtype are shown in the Figure. Overall, 99.0\% (593/599 cases with known subtype) of hospitalisations for laboratoryconfirmed influenza enrolled in participating hospitals were due to influenza $A$; influenza $A\left(\mathrm{H}_{3} \mathrm{~N}_{2}\right)$ accounted for $99.1 \%(n=214)$ of the 216 cases with known subtype.

Hospitalised patients with laboratory-confirmed influenza were older than test-negative controls (mean age: 77.7 (standard deviation, SD: 15.2) years vs 70.9 (SD: 16.6) years, respectively; $p<0.001) ; 68.8 \%(n=413)$ of cases were over 75 years of age compared with only $44.8 \%(n=211)$ of test-negative controls ( $p<0.001)$. The majority of both cases and controls were female (54.2\% ( $(n=325)$ and $52.7 \% \quad(n=248)$, respectively; $\mathrm{p}=0.62$ ) and had one or more underlying medical comorbidity (97.2\% (512/527) and 97.0\% (382/394), respectively; $p=0.85$ ) (Table 1$).$ A total of $399(66.5 \%)$ cases and $300(63.7 \%)$ test-negative controls reported receipt of the 2014/15 influenza vaccine. Among those for whom outcome data were available, rates of admission to an intensive-care unit (10.1\% (650/497) vs $11.1 \%$ (35/315); $p=0.64)$, need for mechanical ventilation $(4.2 \%(16 / 377)$ vs $4.6 \%(14 / 303) ; p=0.85)$, and death (7.9\% (28/356) vs $9.7 \%(23 / 237) ; p=0.46)$ did not differ between patients with laboratory-confirmed influenza and test-negative controls.

The overall and age-stratified VE for the prevention of laboratory-confirmed influenza-related hospitalisation in the adults in our study are shown in Table 2. Overall interim VE of 2014/15 influenza vaccines in persons aged 16 years and older, adjusted for age and the presence of one or more medical comorbidities, was $-16.8 \%$ (90\% Cl: -48.9 to 8.3 ). Among adults 65 years and older, the interim adjusted VE was $-25.4 \%(90 \% \mathrm{Cl}$ : -65.0 to 4.6$)$ and among adults under 65 years of age, the interim adjusted VE was $10.8 \%(90 \% \mathrm{Cl}:-50.2$ to 47.0). Overall adjusted VE against confirmed influenza $\mathrm{A}\left(\mathrm{H}_{3} \mathrm{~N}_{2}\right)$ was $-22.0 \%$ (90\% Cl: -66.5 to 10.7$)$. Among adults 65 years and older, the interim adjusted influenza $A\left(\mathrm{H}_{3} \mathrm{~N}_{2}\right)$ VE was $-32.9 \%(90 \% \mathrm{Cl}:-90.0$ to 7.0$)$ and among adults younger than 65 years of age, the interim adjusted VE was $7.5 \%$ (90\% $\mathrm{Cl}:-78.3$ to 52.0$)$.

\section{Discussion}

The 2014/15 influenza season in Canada has been dominated by circulation of influenza $A\left(\mathrm{H}_{3} \mathrm{~N}_{2}\right)$ viruses [1] and this is consistent among hospitalised influenza cases admitted to SOS Network hospitals. Genetic and antigenic characterisation of circulating influenza strains by the National Microbiology Laboratory (NML) in Winnipeg, Manitoba, Canada has demonstrated a predominance of drifted influenza $\mathrm{A}\left(\mathrm{H}_{3} \mathrm{~N}_{2}\right)$ strains, indicating a poor match between the circulating influenza $A\left(\mathrm{H}_{3} \mathrm{~N}_{2}\right)$ virus and the $2014 / 15 A\left(\mathrm{H}_{3} \mathrm{~N}_{2}\right)$ northern hemisphere influenza vaccine strain $[1,3]$. Overall, less than $1 \%$ of viruses characterised were well matched to $A /$ Texas/50/2012, the $A\left(\mathrm{H}_{3} \mathrm{~N}_{2}\right)$ component of the $2014 / 15$ influenza vaccines. Of $55 \mathrm{~A}\left(\mathrm{H}_{3} \mathrm{~N}_{2}\right)$ viruses 
Characteristics of laboratory-confirmed influenza cases $(n=600)$ and test-negative controls $(n=471)$ included in the interim analysis of 2014/15 influenza vaccine effectiveness, Serious Outcomes Surveillance Network of the Canadian Immunization Research Network, 15 November-10 January 2015

\begin{tabular}{|c|c|c|c|c|}
\hline Characteristics & $\begin{array}{c}\text { Cases } \\
n=600 \\
n(\%)^{a}\end{array}$ & $\begin{array}{c}\text { Controls } \\
n=471 \\
n(\%)^{\mathrm{a}}\end{array}$ & $\begin{array}{c}\text { Total } \\
n=1,071 \\
n(\%)^{a}\end{array}$ & P value \\
\hline Mean age (SD); range & $77.7(15.2)$ years; $18-105$ & $70.9(16.6)$ years; $19-101$ & $74.7(16.2)$ years; $18-105$ & $<0.001$ \\
\hline \multicolumn{5}{|l|}{ Age group } \\
\hline $16-49$ years & $42(7.0)$ & $55(11.7)$ & $97(9.1)$ & \multirow{4}{*}{$<0.001$} \\
\hline $50-64$ years & $41(6.8)$ & $79(16.8)$ & $120(11.2)$ & \\
\hline $65-75$ years & $104(17.3)$ & $126(26.8)$ & $230(21.5)$ & \\
\hline 275 years & $413(68.8)$ & $211(44.8)$ & $624(58.3)$ & \\
\hline \multicolumn{5}{|l|}{ Sex } \\
\hline Female & $325(54.2)$ & $248(52.7)$ & $573(53.5)$ & 0.62 \\
\hline \multicolumn{5}{|l|}{ Inclusion criteria at enrolment } \\
\hline Pneumonia & $179(29.8)$ & $223(47.3)$ & $402(37.5)$ & $<0.001$ \\
\hline Acute exacerbation of COPD or asthma & $82(13.7)$ & $121(25.7)$ & $203(19.0)$ & $<0.001$ \\
\hline Unexplained sepsis & $15(2.5)$ & $25(5.3)$ & $40(3.7)$ & 0.02 \\
\hline Any other acute respiratory illness ${ }^{c}$ & $414(69.0)$ & $188(39.9)$ & $602(56.2)$ & $<0.001$ \\
\hline Invasive pneumococcal disease & $1(0.2)$ & $6(1.3)$ & $7(0.7)$ & 0.05 \\
\hline One or more medical comorbidities ${ }^{d}$ & $512 / 527(97.2)$ & $382 / 394(97.0)$ & $894 / 921(97.1)$ & 0.85 \\
\hline \multicolumn{5}{|l|}{ Received $2014 / 15$ influenza vaccine ${ }^{e}$} \\
\hline All age groups & $399(66.5)$ & $300(63.7)$ & $699(65.3)$ & 0.37 \\
\hline $16-49$ years & $13(31.0)$ & $22(40.0)$ & $35(36.1)$ & 0.40 \\
\hline $50-64$ years & $21(51.2)$ & $44(55.7)$ & $65(54.2)$ & 0.70 \\
\hline $65-75$ years & $70(67.3)$ & $86(68.3)$ & $156(67.8)$ & 0.88 \\
\hline$>75$ years & $295(71.4)$ & $148(70.1)$ & $443(71.0)$ & 0.78 \\
\hline \multicolumn{5}{|l|}{ Course in hospital ${ }^{d}$} \\
\hline Admitted to intensive-care unit & $50 / 497(10.1)$ & $35 / 315(11.1)$ & $85 / 812(10.5)$ & 0.64 \\
\hline Required mechanical ventilation & $16 / 377(4.2)$ & $14 / 303(4.6)$ & $30 / 680(4.4)$ & 0.85 \\
\hline Died in hospital & $28 / 356(7.9)$ & $23 / 237(9.7)$ & $51 / 593(8.6)$ & 0.46 \\
\hline
\end{tabular}

COPD: chronic obstructive pulmonary diseas; SD: standard deviation.

a Unless otherwise indicated.

b Cases vs controls.c Includes those with any other respiratory infection or diagnosis; or any respiratory or influenza-like symptom (e.g. dypsnoea, cough, sore throat, myalgia, arthralgia, fever).

d Data on medical comorbidities and course in hospital are reported as rates among those with available data. The denominator represents the number of patients from whom this data point was available.

e The denominators are the numbers in the respective age group.

tested by haemagglutinin inhibition assay, only one virus was antigenically similar to $A / T e x a s / 50 / 2012$. Five viruses showed reduced antibody titres to $\mathrm{A} /$ Texas/50/2012 and 49 were antigenically similar to A/Switzerland/9715293/2013. Among 250 influenza $\mathrm{A}\left(\mathrm{H}_{3} \mathrm{~N}_{2}\right)$ viruses genetically characterised by sequence analysis, 249 belonged to a drifted genetic group predicted to have reduced titres to the vaccine strain $A$ / Texas/50/2012 [1].

Our interim VE estimates derived from influenzarelated hospitalisations from 15 November 2014 to January 10, 2015 demonstrate overall lack of effectiveness of the 2014/15 influenza vaccine for the prevention of influenza-related hospitalisation in adults. While the relationship between VE and antigenic match is not always clear, and VE cannot be predicted directly from virological surveillance, our results might have been anticipated given that over $99 \%$ of circulating $\mathrm{A}\left(\mathrm{H}_{3} \mathrm{~N}_{2}\right)$ strains characterised by the $\mathrm{NML}$ have been antigenically drifted from the $A\left(\mathrm{H}_{3} \mathrm{~N}_{2}\right)$ vaccine strain, and were similar to the antigenically distinct A/Switzerland/9715293/2013, which is the $A\left(\mathrm{H}_{3} \mathrm{~N}_{2}\right)$ component recommended for the 2015 southern hemisphere vaccine $[1,7]$. Our overall interim influenza $\mathrm{A}\left(\mathrm{H}_{3} \mathrm{~N}_{2}\right)$ VE of $-22 \%(90 \% \mathrm{Cl}:-66.5$ to 10.7$)$ is lower than the interim VE against influenza $A\left(\mathrm{H}_{3} \mathrm{~N}_{2}\right)$ laboratory-confirmed influenza associated with medically attended acute respiratory illness reported in the US (22\% (95\% Cl: 5 to 35) [2] for a variety of reasons. Most importantly, although both Canada and the US have experienced early influenza seasons characterised by 
Interim estimates of 2014/15 influenza vaccine effectiveness in the prevention of laboratory-confirmed influenza-related hospitalisation in adults from the Serious Outcomes Surveillance Network of the Canadian Immunization Research Network, 15 November 2014-January 10, 2015 (n=1,071)

\begin{tabular}{|c|c|c|c|}
\hline Cohort & $\begin{array}{c}\text { Vaccine effectiveness estimate } \\
\%\end{array}$ & $90 \% \mathrm{Cl}$ & $95 \% \mathrm{Cl}$ \\
\hline \multicolumn{4}{|l|}{ Unadjusted } \\
\hline \multicolumn{4}{|l|}{ All strains } \\
\hline Overall & -13.1 & -39.9 to 8.5 & -45.7 to 12.1 \\
\hline Age $\geq 65$ years & -5.7 & -35.9 to 17.8 & -42.6 to 21.6 \\
\hline Age $<65$ years & 28.5 & -13.7 to 55.1 & -24.3 to 58.9 \\
\hline \multicolumn{4}{|c|}{ Confirmed $\mathrm{A}\left(\mathrm{H}_{3} \mathrm{~N}_{2}\right)$} \\
\hline Overall & -14.8 & -52.8 to 13.8 & -61.4 to 18.4 \\
\hline Age $\geq 65$ years & -9.6 & -53.2 to 21.6 & -63.4 to 26.5 \\
\hline Age $<65$ years & 17.6 & -53.3 to 55.7 & -72.7 to 60.7 \\
\hline \multicolumn{4}{|l|}{ Adjusted $^{a}$} \\
\hline \multicolumn{4}{|l|}{ All strains } \\
\hline Overall & -16.8 & -48.9 to 8.3 & -56.0 to 12.5 \\
\hline Age $\geq 65$ years & -25.4 & -65.0 to 4.6 & -73.8 to 9.5 \\
\hline Age $<65$ years & 10.8 & -50.2 to 47.0 & -66.0 to 52.1 \\
\hline \multicolumn{4}{|c|}{ Confirmed $\mathrm{A}\left(\mathrm{H}_{3} \mathrm{~N}_{2}\right)$} \\
\hline Overall & -22.0 & -66.5 to 10.7 & -76.8 to 15.9 \\
\hline Age $\geq 65$ years & -32.9 & -90.0 to 7.0 & -103.5 to 13.2 \\
\hline Age $<65$ years & 7.5 & -78.3 to 52.0 & -102.2 to 57.7 \\
\hline
\end{tabular}

$\mathrm{Cl}$ : confidence interval.

a Adjusted for age and presence of one or more medical comorbidities [4].

dominant circulation of influenza $\mathrm{A}\left(\mathrm{H}_{3} \mathrm{~N}_{2}\right)$, only approximately two thirds of circulating $\mathrm{A}\left(\mathrm{H}_{3} \mathrm{~N}_{2}\right)$ viruses in the US are genetically and antigenically drifted from the $2014 / 15$ vaccine strain compared with more than $99 \%$ of circulating strains in Canada $[1,2,8]$. Both the US and Canadian interim VE estimates reported thus far have assessed VE against laboratory-confirmed medically attended acute respiratory illness in the community among both children and adults and thus might be predicted to be higher than our estimates of VE in the prevention of influenza-associated hospitalisation in predominantly elderly patients with medical comorbidities. While only $14 \%$ of cases included in the US VE analysis and $16 \%$ of cases in the Canadian Sentinel Physician Surveillance Network analysis were 65 years or older, $69 \%$ of our hospitalised cases were over the age of 75 years and $97 \%$ of adults in our study population had medical comorbidities, which put them at increased risk of influenza complications [2,3]. Point estimates of overall adjusted VE in adults younger than 65 years of age in our study were more comparable to those reported in the US (10.8\% in our study vs $16 \%$ in 18-49 year-olds in the US) and in Canada (6\% in 20-64 year-olds), although none of these estimates were statistically significant $[2,3]$.

Canada last experienced an influenza $A\left(\mathrm{H}_{3} \mathrm{~N}_{2}\right)$ dominant influenza season in $2012 / 13$. During that season, only $47 \%$ of hospitalised laboratory-confirmed influenza patients in the SOS Network were over the age of 75 years and $92 \%$ had medical comorbidities, compared with $69 \%$ of cases over the age of 75 years and presence of comorbidities in $97 \%$ this year [9]. The percentage of patients in 2012/13 requiring admission to an intensive-care unit, requiring mechanical ventilation, or dying as a result of influenza was similar to, but marginally higher than, the current season (15\% vs $11 \%$; $9 \%$ vs $4 \%$; and $9 \%$ vs $8 \%$, respectively), possibly reflecting reduced intensity of care in the elderly individuals this season [9]. During the 2012/13 season, VE for the prevention of influenza $\mathrm{A}\left(\mathrm{H}_{3} \mathrm{~N}_{2}\right)$-associated hospitalisation was $38 \%$ [9]. While circulating $\mathrm{A}\left(\mathrm{H}_{3} \mathrm{~N}_{2}\right)$ isolates during the $2012 / 13$ season were antigenically similar to the $A /$ Victoria/361/2011 vaccine strain, they were antigenically distinct from the egg-adapted vaccine strain used in vaccine production, potentially accounting for the observed suboptimal VE [10].

As hospital care for adults is provided in more than one hospital in most cities across Canada, the populationbase, or catchment, for hospitals participating in the SOS Network cannot be readily assessed. We do, however, assess the representativeness of the cases admitted to SOS Network hospitals by comparing them to all hospitalised cases reported to the Public Health Agency of Canada through available surveillance mechanisms, 
most notably, reporting from the provincial and territorial governments. Each season, the strain distribution of hospitalised cases enrolled across the SOS Network as well as the age distribution, immunisation coverage rates, and outcomes is comparable to that reported by the Public Health Agency of Canada in Canada's FluWatch, providing reassurance that the estimates of VE generated by the SOS Network should be generalisable in Canada.

Our findings are subject to several limitations. Because large numbers of patients are needed to demonstrate statistical significance when VE estimates are low, our estimates of VE in adults are imprecise and it is possible that low, but statistically significant, effectiveness of the 2014/15 vaccine is expected to be demonstrated as the accumulated sample size grows during the remainder of the influenza season. Because the influenza season thus far has been characterised by almost exclusive circulation of a drifted influenza $A\left(\mathrm{H}_{3} \mathrm{~N}_{2}\right)$ virus in Canada, it is possible that end-of-season VE estimates may differ if circulation of influenza $A\left(\mathrm{H}_{1} \mathrm{~N}_{1}\right)$ or influenza $B$ viruses occurs later this season. Limited characterisation of influenza $A\left(\mathrm{H}_{1} \mathrm{~N}_{1}\right)$ and influenza $B$ strains circulating in Canada thus far suggest a good match to vaccine strains [1]; thus vaccine recipients may still benefit from protection against these strains should they begin to circulate later in the season. In that case, fully adjusted end-of-season VE estimates may be higher than our interim estimates. Because estimates have not yet been fully adjusted for a variety of potential confounding factors particularly important for elderly patients (e.g. frailty) and a final analysis using a matched case-control design in which cases will be matched with controls by hospital site, age strata ( $<65$ years vs $\geq 65$ years) and date of admission has not yet been performed, the final matched and fully adjusted estimates might differ from the interim partially adjusted estimates presented here. Matching is not feasible at the stage of the interim analysis and is therefore conducted as an unmatched analysis. Finally, because for some subjects contributing to the current interim estimates, the self-reported influenza immunisation status could not be verified using the immunisation provider or an immunisation registry, it cannot be fully excluded that some misclassification may have occurred. However, based on our experiences in prior seasons, there is high concordance between selfreport and provider-reported immunisation status, so the expected impact of misclassification is expected to be very low.

Using data from 15 November to 10 January 2015, the demonstrated lack of effectiveness of the 2014/15 seasonal influenza vaccines for the prevention of influenza-associated hospitalizations in adults, particularly in adults over the age of 65 years, highlights the importance of employing additional strategies to control and prevent the spread of influenza, such as frequent hand cleansing, encouraging people to stay home when sick and encouraging proper cough etiquette. Furthermore, it is critical that healthcare providers consider a diagnosis of influenza in all patients presenting with acute respiratory illness irrespective of immunisation history and test patients for influenza as appropriate. Healthcare providers should be aware that hospitalised adults with laboratory-confirmed influenza frequently do not present with influenza-like-illness [11]. Thus, they should test for influenza and implement contact and droplet precautions for all patients being admitted to hospitals with an acute respiratory illness during the influenza season while awaiting results, in order to minimise nosocomial influenza transmission.

Appropriate use of antiviral medication in the treatment of suspected cases of influenza is critical in seasons characterised by a low VE, such as the current season in Canada. In order to reduce severe complications such as hospitalisation and potential death among vulnerable individuals, the Association of Medical Microbiology and Infectious Disease Canada recommends the prompt use of neuraminidase inhibitors (oseltamivir or zanamivir) in hospitalised patients, patients with progressive, severe or complicated disease, and patients at high risk of complications from influenza regardless of their vaccination status [12]. Because the benefit of treatment with antiviral medications is maximal when treatment is started early in the course of illness, ideally within 48 hours of symptom onset, healthcare providers should maintain a high index of suspicion of influenza in patients presenting with acute respiratory illness, irrespective of their immunisation status, and should start antivirals empirically while awaiting influenza testing [12].

While the relationship between vaccine strain and circulating strain mismatch is not fully understood and variable effectiveness by match has been observed in past seasons, the suboptimal VE observed in the current season and in prior seasons with significant mismatch between circulating viruses and vaccine strains reflects, at least in part, the challenge in current vaccine technologies, which require determination of the vaccine composition months ahead of the influenza season and highlights the urgent need for the continued development of new vaccine technologies [7]. Stakeholders must continue to refine key elements that must be considered to optimise vaccine strain selection and vaccine manufacturers should strive to improve vaccine formulations to optimise cross-protection, particularly for influenza $\mathrm{A}\left(\mathrm{H}_{3} \mathrm{~N}_{2}\right)$ viruses [13]. While influenza vaccination remains the most important means of preventing influenza, ongoing assessment of VE and provision of mid-season VE estimates for the prevention of influenza-related hospitalisation in adults is critical to understanding the periodic impact of circulating and vaccine strain mismatch on vaccine performance and to inform public health communication with respect to adjunctive preventive strategies, particularly in years of suboptimal VE. 


\section{Acknowledgements}

This study was funded by the Canadian Institutes of Health Research (Grants \#124309 and \#137470) and through a Collaborative Research Agreement with GlaxoSmithKline Biologicals SA. The authors wish to thank Aurélie Le Plain for her invaluable contribution to data validation and the dedicated SOS Network Surveillance monitors whose tremendous efforts make this study possible.

\section{Conflict of interest}

FH and RS are employed by the GlaxoSmithKline Group of Companies. VS reports that he was employed by GSK Vaccines at the time of the study and reports ownership of stock options and/or restricted shares in the GlaxoSmithKline Group of Companies; GDS is employed by Business and Decision Life Sciences (on behalf of GlaxoSmithKline Vaccines); SAM reports research grants from GlaxoSmithKline, Pfizer, Sanofi Pasteur, personal fees from Merck, Pfizer; JEM personal fees from GlaxoSmithKline, Sanofi Pasteur; TFH reports research grants from GlaxoSmithKline, Pfizer; MKA reports research grants from GlaxoSmithkline, Pfizer; JL reports research grants from GlaxoSmithKline, Pfizer.

\section{Authors' contributions}

SAM, MKA, LY, FH, TFH, ME, AA, AM, JEM, ML, DMC, VS were involved in the conception and design of the study; SAM, MKA, AM, JEM, ML were responsible for acquisition of data; TFH, ME conducted/supervised the CIRN SOS Network central laboratory; SAM, MKA, LY, FH, DMC, AM, JEM, ML, RS, GDS analysed and interpreted the data; SAM drafted the manuscript; all authors revised the manuscript critically for important intellectual content; all authors reviewed and approved the final draft of the manuscript

Investigators of the Serious Outcomes Surveillance Network of the Canadian Immunization Research Network include the following individuals:

D Smyth, Moncton, New Brunswick; D Webster, Saint John, New Brunswick; SA McNeil, Halifax, Nova Scotia; MK Andrew, Halifax, Nova Scotia; TF Hatchette, Halifax, Nova Scotia; A Ambrose, Halifax, Nova Scotia; D MacKinnon-Cameron, Halifax, Nova Scotia; M ElSherif, Halifax, Nova Scotia; J LeBlanc, Halifax, Nova Scotia; JM Langley, Halifax, Nova Scotia; SA Halperin, Halifax, Nova Scotia; L Ye, Halifax, Nova Scotia; B Smith, Halifax, Nova Scotia; M Semret, Montreal, Quebec; G Boivin, Quebec City, Quebec; S Trottier, Quebec City, Quebec; L Valiquette, Sherbrooke, Quebec; A McCarthy, Ottawa, Ontario; JE McElhaney, Sudbury, Ontario; A McGeer, Toronto, Ontario; K Green, Toronto, Ontario; B Coleman, Toronto, Ontario; K Katz, Toronto, Ontario; D Richardson, Toronto, Ontario; J Powis, Toronto, Ontario; M Loeb, Hamilton, Ontario; W Bowie, Vancouver, British Columbia.

\section{References}

1. Public Health Agency of Canada (PHAC). FluWatch report: January 4 to January 10, 2015 (Week 1). Ottawa: PHAC; 2015. Available from: http://www.phac-aspc.gc.ca/fluwatch/14-15/ w01_15/index-eng.php

2. Flannery B, Clippard J, Zimmerman RK, Nowalk MP, Jackson $M L$, Jackson LA, et al. Early estimates of seasonal influenza vaccine effectiveness - United States, January 2015. MMWR Morb Mortal Wkly Rep. 2015;64(1):10-5. Available from: http:// www.cdc.gov/mmwr/preview/mmwrhtml/mm6401a4.htm?s cid=mm6401a4_w PMID:25590680
3. Skowronski DM, Chambers C, Sabaiduc S, De Serres G, Dickinson JA, Winter AL, et al. Interim estimates of 2014/15 vaccine effectiveness against influenza $A\left(\mathrm{H}_{3} \mathrm{~N}_{2}\right)$ from Canada's Sentinel Physician Surveillance Network, January 2015. Euro Surveill. 2015;20(4):pii=21022. Available from: http://www. eurosurveillance.org/Viewarticle.aspx?Articleld=21022

4. National Advisory Committee on Immunization. Statement on seasonal influenza vaccine for 2014-2015. Ottawa: Public Health Agency of Canada; 2014. Available from: http://www. phac-aspc.gc.ca/naci-ccni/assets/pdf/flu-grippe-eng.pdf

5. Centers for Disease Control and Prevention (CDC). CDC health advisory regarding the potential for circulation of drifted influenza $\mathrm{A}\left(\mathrm{H}_{3} \mathrm{~N}_{2}\right)$ viruses. Centers for Disease Control and Prevention Health Alert Network. Atlanta, GA: CDC: 3 Dec 2014. Available from: http://emergency.cdc.gov/HAN/hano0374.asp

6. McNeil S, Shinde V, Andrew M, Hatchette T, Leblanc J, Ambrose $A$, et al. Interim estimates of 2013/14 influenza clinical severity and vaccine effectiveness in the prevention of laboratoryconfirmed influenza-related hospitalisation, Canada, February 2014. Euro Surveill. 2014;19(9):20729. http://dx.doi. org/10.2807/1560-7917.ES2014.19.9.20729. PMID:24626207

7. Kelly HA, Sullivan SG, Grant KA, Fielding JE. Moderate influenza vaccine effectiveness with variable effectiveness by match between circulating and vaccine strains in Australian adults aged 20-64 years, 2007-2011. Influenza Other Respi Viruses. 2013;7(5):729-37. http://dx.doi.org/10.1111/irv.12018. PMID:23078073

8. Centers for Disease Control and Prevention (CDC). FluView. 2014-2015 Influenza Season Week 2 ending January 17, 2015. U.S. Virologic Surveillance, Influenza Virus Characterization. Atlanta, GA: CDC. [Accessed 31 Jan 2015]. Available from: http://www.cdc.gov/flu/weekly

9. McNeil SA, Ambrose A, Andrew M, Diaz Mitoma F, Boivin G, Bowie W, et al. Effectiveness of 2012/13 seasonal influenza vaccines in the prevention of influenza-related hospitalization in Canadian adults: A Public Health Agency of Canada/ Canadian Institutes of Health Research (PCIRN) Serious Outcomes Surveillance Network Study. Abstract P2-511. Presented at Options for the Control of Influenza VIII, Cape Town, South Africa, 5-10 September, 2013. Available from: http://optionsviii.controlinfluenza.com/optionsviii/assets/File/ Options_VIII_Abstracts_2013.pdf

10. Skowronski DM, Janjua NZ, De Serres G, Sabaiduc S, Eshaghi A, Dickinson JA, et al. Low 2012-13 influenza vaccine effectiveness associated with mutation in the egg-adapted $\mathrm{H}_{3} \mathrm{~N}_{2}$ vaccine strain not antigenic drift in circulating viruses. PLOS ONE. 2014;9(3):e92153. http://dx.doi.org/10.1371/ journal.pone.0092153. PMID:24667168

11. McNeil SA, Krajden O, Gajic S, Elsherif M, Green K, McGeer A, et al. Performance characteristics of influenza-like-illness case definitions in predicting influenza in hospitalized Canadian adults. Presented at IDWeek 2012, 17-21 Oct 2012, San Diego, CA. Available from: https://idsa.confex.com/idsa/2012/ viewsessionpdf.cgi

12. Aoki FY, Allen UD, Stiver HG, Evans GA. The use of antiviral drugs for influenza: Guidance for practitioners 2012/2013. Can J Infect Dis Med Microbiol. 2012;23(4):e79-92. PMID:24294283

13. World Health Organization (WHO). zrd WHO informal consultation for improving influenza vaccine virus selection. 1 to 3 April 2014, Geneva, Switzerland. Geneva: WHO. [Accessed 15 Jan 2015]. Available from: http://www.who.int/influenza/ vaccines/virus/3rdmtg_improve_vaccine_virus_selection/en/ 